\title{
THE DIFFERENCES BETWEEN INDIVIDUAL-TYPOLOGICAL PECULIARITIES OF BELIEVERS IN RELATIONSHIP WITH THE TYPE OF THEIR RELIGIOUS ORIENTATION
}

\author{
Svetlana P. Politova ${ }^{1}$ \\ Zoya V. Silaeva ${ }^{2}$ \\ Alina R. Bikusheva ${ }^{3}$
}

\begin{abstract}
The paper is devoted to the problems of the psychology of believers, which are relevant to modern science. The paper analyses the results of a study on the relationship between the characteristics of a person's religiosity and his/her individual typological characteristics. To conduct the study, a theoretical analysis was used, as well as
\end{abstract}

control between believers with an reliable and valid methods of psychological diagnosis were applied: a scale of religious orientation by $\mathrm{G}$. Allport and D. Ross, an individually typological questionnaire by L.N. Sobchik, test "Study of the subjective control level" (SCL); processing of the results was carried out using mathematical statistics methods, external and internal religious orientation, namely that people with an external religious orientation are more extroverts than introverts. It was also found that external religiosity is inversely related to most indicators of the locus of control. The results of the study are important to expand understanding of the psychology of believers. An important conclusion that the study allows us to draw is the fact that the selection of believers by their individual typological characteristics is not uniform, which means that research on the psychology of believers should be carried out in the context of their religious orientation.

including t-student test and correlation analysis. The study found differences in the level of subjective personality

\footnotetext{
${ }^{1}$ Kazan Federal University.

${ }^{2}$ Kazan Federal University, Tel. : 8 (843) 233-70-47. e-mail: silaeva-zoya@mail.ru

${ }^{3}$ Kazan Federal University
} 
Keywords: the psychology of religion, study of religiosity, external religiosity, internal religiosity, locus of control.

\section{Introduction}

Religious institutions are a source of historically established norms and values participating in the formation of a person's worldview, his/her motives and character, as well as individual and typological characteristics as a whole. However, at the moment there are not many practical studies that reveal the result of this influence in domestic science. Therefore, the question of the interaction between religious faith and personality traits remains open.

Despite the variety of approaches in psychology to the interpretation of the content of such phenomenon as a character, the positions of many researchers coincide with each other in the fact that a character is revealed in an individual personality reaction, which is formed in relation of a person to other people and to society as a whole. It can be said that character denotes a difference in the variety of qualities belonging to an individual and ensuring interaction. Therefore, characteristic features are often associated with the distinctive features of a person, which reveal his/her essence, explain his/her behavioural logic.

A great influence on individual typological features can be exerted by life circumstances, as well as by upbringing. The latter, in turn, is largely based on the customs and norms of a given society. A religious worldview along with its values and patterns of behaviour appears as the most common in the system of a person's position in relation to the world around him/her and forms a specific "model of the world" as a psychological construct (Granovskaya, 2010).

As B. S. Bratus remarked, faith is a "general psychological phenomenon" that reveals itself in various forms, and one of its forms is religious faith; its phenomenon gives rise to many new questions, the answers to which can be found using the resources of psychology (Bratus, 2009).

Religious faith is actively embedded in the human psyche, in a personal model of the world. And this, in turn, can be reflected in the formed features of the character of an individual. G. Allport notes that "the presence of moral ideals, conscience and religious beliefs in a child (or an adult) is 
a very important fact for studying their personality, as these are features of their internal structure" (Allport \& Ross, 1967).

Since each person has a very individual personality, psychological characteristics, each person individually and differently perceives the life positions accepted in society. Consequently, the perception and understanding of religious faith can also be uneven.

Exploring the religious faith and the sphere of its interaction with the human psyche, many domestic and foreign modern scholars adhere to its one or another typological variant.

As a result of taking into account the peculiarities of the relationship between individuals to religious faith, scientists have discovered differences in the building up of worldview and behavioural strategies by people. So, for example, Canadian researchers, dividing religious motivation into 4 types, established their relationship with personal adaptation (O'Connor \& Vallerand, 1990). Belgian scholars have discovered that autonomous religiosity is associated with anti-authoritarian tendencies in the interpretation of sacred texts, and also in relation to new experiences (Neyrinck et al., 2006). American researchers have shown a relationship between types of religiosity and mental health (Ryan et al., 1993). Also, R.S. Titov, while studying Orthodox students, found differences in their psychological well-being, sharing an autonomous and controlled motivation for religion faith (Titov, 2012). Similarly, we can assume that individual typological features largely depend on the meaning that the believer puts into his/her religious faith since this affects the distinctive features of the individual's worldview and behaviour.

In the studies, we conducted earlier, statistically significant differences were revealed between the type of religiosity and the indicator of personality anxiety, as well as other characterological features. A revealed fact made it possible to put forward a hypothesis that there is a relationship between the individual typological characteristics of a person and the characteristics of the religious orientation of believers (Bikusheva, 2017; Politova \& Bikusheva, 2016).

The object of the study was the individual typological characteristics of 
believers. The subject is their relationship with the characteristics of religious orientation.

\section{Methods}

In order to verify the hypothesis, a special study was organized in which 39 people aged 24 to 67 years participated. All respondents were aware of the rules for conducting research and processing the results, on the basis of which they gave their consent to participate in the study.

Methods for testing the hypothesis included the methods of psychological diagnosis: the scale of religious orientation by G. Allport and D. Ross, individual and typological questionnaire by L.N. Sobchik, test "Study of the subjective control level" (SCL). Despite the existing criticism of the approach in which the external and internal religious orientations are distinguished, from our point of view, it is this approach that allows us to most accurately differentiate the essential differences of believers (Kirkpatrick \& Hood Jr, 1990).

Information was also additionally collected by the age, gender, level of education and religious identification of the subjects.

The selected methods and additional information provided by the respondents allowed us to analyse 23 indicators:

P1 (internal religious orientation);

P2 (external religious orientation);

P3 (extraversion);

P4 (spontaneity);

P5 (aggressiveness);

P6 (rigidity);

P7 (introversion);

P8 (sensitivity);

P9 (anxiety);

P10 (lability);

P11 (general internality);

P12 (internality in the field of achievements);

P13 (internality in the field of failures);

P14 (internality in the field of family relations);

P15 (internality in the field of industrial relations);

P16 (internality in the field of interpersonal relations);

P17 (internality in the field of health and disease); 
P18 (age);

P19 (level of education);

P20 (religious affiliation);

P21 (gender);

P22 (false);

P23 (aggravation).

To calculate the results, methods of mathematical statistics were used: calculation of short statistics, statistical analysis of differences by the Student t-test, as well as Pearson's linear correlation analysis.

\section{Results And Discussion}

Initially, questionnaires were examined according to indicators of external and internal religious orientation according to the method of $\mathrm{G}$. Allport. The sample was divided as follows:

1) Low external religious orientation ( $\downarrow$ External) - 19 people;

2) High external religious orientation ( $\uparrow$ External) - 20 people;

3) High internal religious orientation ( $\uparrow$ Inside) - 12 people;

4) Low internal religious orientation ( $\downarrow$ Inside) - 27 people.

The ratio of respondents participating in the study by the level of religious orientation, as well as by qualitative characteristics, can be presented in the following table:

Table 1. Sample Features *

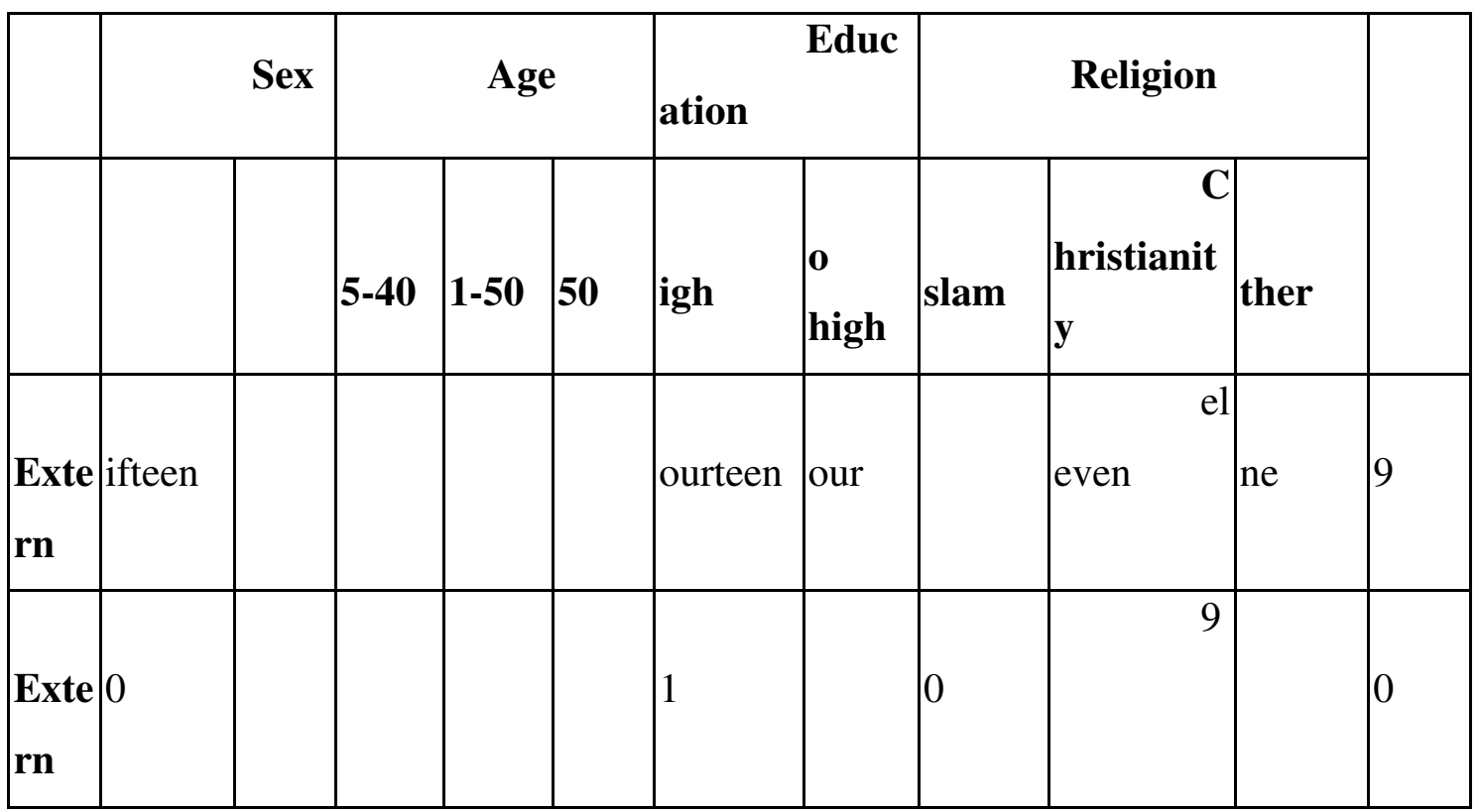




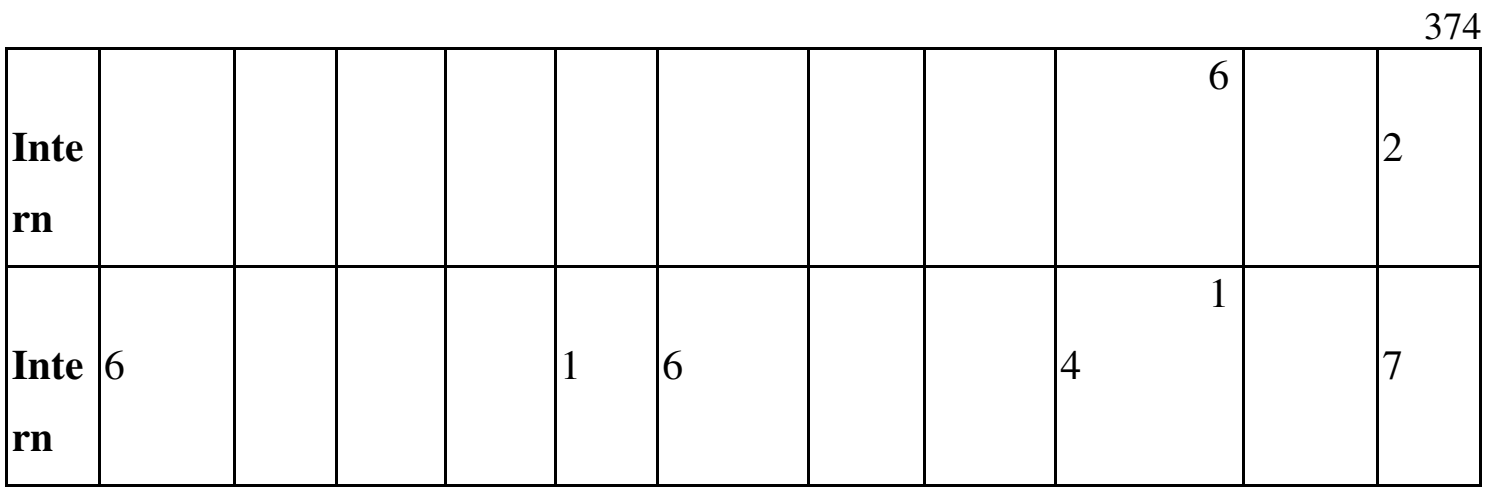

Note: ${ }^{*}$ not all subjects indicated their socio-demographic characteristics

As a result of analysis by the Student t-criterion for unrelated samples between the first and second groups, statistically significant differences were found in such indicators as $\mathrm{P} 12$ (internality in the field of achievements) $(\mathrm{t}=2.256, \mathrm{p} \leq 0.05)$ and P16 (internality in the field of interpersonal relationships $)(t=2.64, \mathrm{p} \leq 0.05)$.

This means that subjects with a low external religious orientation are more inclined than respondents with a high external religious orientation to realize their responsibility in the formation of their social circle, and also consider their role to be very significant in achieving a particular goal.

Pearson's correlation coefficient was also calculated for the same groups. An inverse relationship was found in the first group with an external religious orientation and with such studied personality characteristics as P11 (general internality) ( $\mathrm{r}=-0.5$, $\mathrm{p} \leq 0.05$ ), P13 (internality in the field of failure $)(\mathrm{r}=-0 \quad 58, \mathrm{p} \leq 0.05), \quad \mathrm{P} 15$ (internality in the field of industrial relations) $(\mathrm{r}=-0.5, \mathrm{p} \leq 0.05)$. It turns out that the lower the external religious orientation in this group, the more its participants are able to independently manage their life in general, in the professional sphere and see mainly their guilt in the troubles that have happened.

Also, according to the indicator of internal religious orientation, a positive correlation was found in P3 (extraversion) $(\mathrm{r}=0.61, \mathrm{p} \leq 0.05), \mathrm{P} 5$ (aggressiveness) $(\mathrm{r}=0.48, \mathrm{p} \leq 0.05), \mathrm{P} 6$ (rigidity) $\quad(\mathrm{r}=0.55, \quad \mathrm{p} \leq 0.05), \quad \mathrm{P} 8$ (sensitivity) $(\mathrm{r}=-0.49, \mathrm{p} \leq 0.05)$ in the first group. We can say that for a group with a low external religious orientation, the lower the internal religiosity, the less extroversion, stubbornness in upholding one's point of view, as well as stiffness 
of attitudes are manifested. However, the higher the degree of internal religious orientation, the lower the pessimism in assessing prospects.

In the second group of respondents, a negative correlation between the indicator of external religious orientation and $\mathrm{P} 4$ (spontaneity) $(\mathrm{r}=-0.5, \mathrm{p} \leq 0.05)$ was found. That is, we can say that with a decrease in the indicator of external religious orientation, respondents show more frivolity in deeds and actions. However, in this group, in terms of internal religious orientation, no reliable relationship with characterological features was found.

As for the study of the third and fourth groups, no statistically significant values by Student's t-test were found.

But the correlation analysis reveals an inverse relationship between the indicator of external religious orientation and P11 (general internality) $(\mathrm{r}=-0.62, \mathrm{p} \leq 0.05), \mathrm{P} 13$ (internality in the field of failure) $(r=-0.64, p \leq 0,05)$, P14 (internality in the field of family relations $) \quad(\mathrm{r}=-0.6, \quad \mathrm{p} \leq 0.05), \quad \mathrm{P} 15$ (internality in the field of industrial relations) $(\mathrm{r}=-0.62, \mathrm{p} \leq 0.05)$, and $\mathrm{P} 17$ From $(r=-0.58, p \leq 0.05)$. According to the internal religious orientation of this group, no reliable relationships were found.

It can be found that for consistently internal religious people who have a low external religious orientation, the internal type of subjective control is more characteristic in general, as well as in achieving goals, creating interpersonal relationships, understanding about illnesses and in professional activities.

As a result of the same analysis, in the fourth group, a negative correlation between indicators of external religious orientation and P3 (extraversion) $(\mathrm{r}=-0.45, \mathrm{p} \leq 0.05), \mathrm{P} 4$ (spontaneity) $(\mathrm{r}=-0.61, \mathrm{p} \leq 0.001), \mathrm{P} 10$ (lability) $\quad(\mathrm{r}=-0.41, \quad \mathrm{p} \leq 0.05), \quad \mathrm{P} 16$ (internality in the field of interpersonal relationships $)(\mathrm{r}=-0.5, \mathrm{p} \leq 0.05)$ was found. A direct relationship was identified with indicator P9 (anxiety) (r $=0.43, \mathrm{p} \leq 0.05)$.

In the same group, in terms of internal religious orientation, a positive correlation with P12 (internality in the field of achievements $)(r=0.41, p \leq 0.05)$ and P16 (internality in the field of interpersonal relations $) \quad(\mathrm{r}=0.42$, $\mathrm{p} \leq 0.05$ ) was found. 
It turns out that for the fourth group of respondents, with a decrease in the level of external religious orientation the degree of extraversion increases, more thoughtlessness in words and actions, as well as motivational instability became more clearly expressed. However, the higher is this indicator, the greater is the degree of anxiety. As for the internal religious orientation, the lower it is, the less typical it is for respondents to consider their role important in life's successes and the formation of a circle of communication.

The study by qualitative characteristics did not give statistically significant differences between the type of religious orientation and the individual typological characteristics of the subjects. However, a positive correlation between the level of education (higher and not higher) and the degree of internality in some areas studied, namely: P11 (general internality) $(\mathrm{r}=3.021, \mathrm{p} \leq 0.05) ; \mathrm{P} 12$ (internality in the field of achievements) $(\mathrm{r}=3,169, \mathrm{p} \leq 0.01) ; \mathrm{P} 13$ (internality in the field of failure $)(r=2.306, p \leq 0.05)$, (internality in the field of industrial relations $)(\mathrm{r}=4.054, \mathrm{p} \leq 0.001)$ was found. This fact can serve as evidence of data reliability.

Also, a negative correlation was found for respondents with higher education between the indicator of external religious orientation and $\mathrm{P} 4$ (spontaneity) $(\mathrm{r}=-0.41, \mathrm{p} \leq 0.05), \mathrm{P} 13$ (internality in the field of failure) $(\mathrm{r}=$ $0.49, \mathrm{p} \leq 0.05$ ), P16 (internality in the field of interpersonal relationships) $(\mathrm{r}=$ $0.54, \mathrm{p} \leq 0.05)$. And from the inside according to $\mathrm{P} 3$ (extraversion) $(\mathrm{r}=0.53$, $\mathrm{p} \leq 0.05)$ and P8 - sensitivity $(\mathrm{r}=-0.53$, $\mathrm{p} \leq 0.05)$.

It turns out that the lower the external religious orientation of people with higher education, the higher the frivolity manifests itself, as well as the higher the awareness of one's responsibility when forming a circle of communication, the degree of understanding of the responsibility of one's guilt in life's failures. And with a decrease in the level of internal religious orientation, the level of extraversion becomes lower, and with its increase, pessimism in views on the future is lower.

As a result of the correlation analysis conducted in a group of female respondents, reliable relationships were 
found between the indicator of external religious orientation and $\mathrm{P} 4$ (spontaneity) ( $\mathrm{r}=-0.41, \mathrm{p} \leq 0.05), \mathrm{P} 11$ (general internality) $(r=-0,48, p \leq 0.05)$, $\mathrm{P} 13$ (in the field of internal failures) $(\mathrm{r}=$ $-0,45, \mathrm{p} \leq 0.05), \mathrm{P} 16$ (internality in interpersonal relations $)(\mathrm{r}=-0,51, \mathrm{p} \leq$ 0.05). And from internal - with P6 (rigidity) $(\mathrm{r}=0.51, \mathrm{p} \leq 0.05)$.

Thus, it can be said that women with a low external religious orientation are more characteristic of thoughtlessness in their statements and actions, a tendency to blame themselves for life's troubles and take responsibility for the established circle of communication. With a low internal religious orientation, subjectivity and criticism with respect to other opinions are less pronounced.

As a result of the same analysis, in the group of male respondents, a reliable relationship was found between external religious orientation and P16 (internality in the field of interpersonal relations) $(\mathrm{r}=-0.61, \mathrm{p} \leq 0.05)$. It turns out that the lower the external religious orientation of males, the higher their internality in interpersonal relations, and similarly, the higher the external religious orientation, the lower this indicator.

It turns out that for men, as well as for women, the lower the external religious orientation, the more likely is the realization of their own responsibility for the established circle of communication. We would also like to note that no statistically significant correlations in internal religiosity were found in this group.

\section{Summary}

So, we can draw the following conclusions as a result of summarising the results of the analysis of the sample by its quantitative and qualitative characteristics:

1) The extraversion index has a direct correlation with an internal religious orientation and an inverse correlation with an external religious orientation. I.e., with an increase in the level of internal religiosity, sociability of a person is manifested to a greater degree.

2) The lack of thought in statements and actions increases with a decrease in the level of external religious orientation. 
3) The external religious orientation indicator is inversely related to five of the seven locus of control indicators, i.e. the higher the level of external religious orientation, the less an individual is inclined to take responsibility in many areas of life and vice versa: with a decrease in the level of external religious orientation, the individual's ability to take responsibility for events in his/her life, successes and failures, etc. becomes more apparent. At the same time, no correlation of locus of control indicators with internal religiosity was found.

\section{Conclusions}

Thus, religious faith influences a person and society. The study carried out allows us to find differences in the level of an identity's subjective control between believers with different types of religious orientation. As a result, our hypothesis about the relationship between individual-typological characteristics of a person and the peculiarities of his/her religious orientation is confirmed.

The results of the study are of absolute significance since today they allow expanding an unfortunately insufficient understanding of the psychology of believers.

In addition, the presence of such significant differences indicates that the selection of believers in their individual typological characteristics is not uniform, which means that studies of the psychology of believers should be carried out in the context of their religious orientation.

\section{Acknowledgements}

The work is performed according to the Russian Government Program of Competitive Growth of Kazan Federal University.

\section{References}

Granovskaya, R.M. Psychology of Faith / R. M. Granovskaya - 2nd edition, revised - St. Petersburg: Piter, 2010. -$576 \mathrm{p}$.

Bratus, B. S. (2009). Psychology and spiritual experience. Counseling Psychology and Psychotherapy, 2009(3), 19-49.

Allport, G. W., \& Ross, J. M. (1967). Personal religious orientation and 
prejudice. Journal of personality and social psychology, 5(4), 432.

O'Connor, B. P., \& Vallerand, R. J. (1990). Religious motivation in the elderly: A French-Canadian replication and an extension. The Journal of Social Psychology, 130(1), 53-59.

Neyrinck, B., Vansteenkiste, M., Lens, W., Duriez, B., \& Hutsebaut, D. (2006). Cognitive, affective and behavioural correlates of internalization of regulations for religious activities. Motivation and Emotion, 30(4), 321-33.

Ryan, R. M., Rigby, S., \& King, K. (1993). Two types of religious internalization and their relations to religious orientations and mental health. Journal of Personality and Social Psychology, 65, 586-596.

Titov, R. S. (2012). Profiles of religious motivation and psychological well-being of Orthodox students. Materials of the International Youth Scientific Forum "Lomonosov-2012". Editor-in-chief A.I.Andreev, A.V. Andriyanov, E.A. Antipov, M.V. Chistyakova. M.: MAX

Press.

Bikusheva, A. R. (2017). Differences in characterological features among believers with different types of religiosity. Final scientific and educational conference of students of Kazan Federal University in 2017: Collection of papers in 6 volumes. Kazan: Kazan University Press,: Institute of Social and Philosophical Sciences and Mass Communications. Institute of Management, Economics and Finance, 5, 12-15.

Politova, S. P., \& Bikusheva, A. R. (2016). The relationship between the level of an individual's anxiety and religiosity. Unified All-Russian Scientific Bulletin, 4, 124-127.

Kirkpatrick, L. A., \& Hood Jr, R. W. (1990). Intrinsic-extrinsic religious orientation: The boon or bane of contemporary psychology of religion?. Journal for the scientific study of religion, 442-462 